\title{
STUDY OF CHIP IGNITION AND CHIP MORPHOLOGY AFTER MILLING OF MAGNESIUM ALLOYS
}

\author{
Ireneusz Zagórski , Józef Kuczmaszewski \\ 1 Department of Production Engineering, Faculty of Mechanical Engineering, Lublin University of Technology, \\ Nadbystrzycka 36, 20-618 Lublin, Poland, e-mail: i.zagorski@pollub.pl, j.kuczmaszewski@pollub.pl
}

Received: 2016.07.20

Accepted: 2016.10.08

Published: 2016.12.01

\begin{abstract}
The paper analyses the impact of specified technological parameters of milling $\left(\mathrm{v}_{\mathrm{c}}, \mathrm{f}_{\mathrm{z}}\right.$, $\left.a_{p}\right)$ on time to ignition. Stages leading to chip ignition were analysed. Metallographic images of magnesium chip were presented. No significant difference was observed in time to ignition in different chip fractions. Moreover, the surface of chips was free of products of ignition and signs of strong oxidation.
\end{abstract}

Keywords: magnesium alloys, chip morphology, time to ignition, chip ignition, highspeed dry milling.

\section{INTRODUCTION}

Although magnesium alloy has been known since the World War II, it is still an interesting structural material. In recent years, there has been a growing interest in magnesium alloys, which are considered as innovative structural materials, particularly in the context of the aircraft industry, which is seen to be at the forefront of modern technology. Manufacturing modern aircraft parts frequently requires quick removal of any existing machining allowance. In addition, the lightness of structure in manufactured aircrafts or helicopters is paramount. In the aerospace industry, the majority of parts is machined by milling, which is a preferred operation in most roughing and finishing applications. Time factor is crucial in removing machining allowance, hence the popularity of high-performance machining methods, such as HSM, HPC or HSC, which however, necessitate the application of state-of-the-art machining centres (high-speed electrospindles) and modern tool materials. High-performance milling offers numerous advantages: high quality surface finish, production costs reduction (grinding is unnecessary), increased efficiency and performance, which leads to reducing machining time. A widespread application of magnesium alloy as a structural material in different branches of industry increases the importance of its rational and precise machining.

\section{THE STATE OF KNOWLEDGE}

The classification of methods for machining magnesium alloys accounts for the character of the realised process and formulated aims [15]: dry or minimum quantity lubrication cutting, with water-immiscible fluids including oils or emulsions. Dry machining of magnesium alloys entails high risk of chip ignition, particularly of small chips. Therefore, chip dimensions and size are crucial in machining magnesium, which arises from susceptibility of magnesium chips to ignition during milling. The analysis of chip fractions and specific weight of formed chips is frequently used to determine machining safety. Chip fragmentation occurs during magnesium alloy milling in certain conditions, and consists in chip segmentation during forming. In addition, ignition in dry cutting can occur as a result of flank 
built-up $[8,9]$. This unfavourable build-up can be reduced if proper tool coating and PCD tools are applied. Another advantage of PCD tools is that the finished surface is of excellent quality, comparable to surfaces finished by grinding. Finishing operations are also used in removing burr from light alloys $\mathrm{Al}$ or $\mathrm{Mg}$, in which case burnishing finds application [14].

Owing to the fact that the risk of ignition in machining is connected with elevated temperature during chip formation, the temperature is usually measured on the chip or in the area just above the rake face. Safety analysis in machining may concern several phenomena, e.g. analysis of chip fractions formed during machining, monitoring ignition in dry cutting, analysis of time to chip ignition (usually away from the machine tool), chip morphology (observation with optic microscopy and SEM) or stages of chip morphology change prior to chip ignition $[4,8,9]$.

It is possible to control the shape and form of chips during milling through adjusting technological parameters of machining. The efforts during machining should be focused on producing chip that would be least susceptible to ignition. A particular type of formed chip, hence the type of ignition, depends on: cutting speed, depth of cut and the type of magnesium alloy machined $[2,3,9]$. It is crucial to determine the ignition point, i.e. temperature characteristic for a given type of $\mathrm{Mg}$ alloy. In related studies, the analyses concern the importance of cerium (Ce) and aluminium (Al) on ignition point and resistance of magnesium alloys to oxidation. Among other factors, studies show that resistance to ignition also depends on the presence of yttrium (Y) $[11,12,19,21]$. Chip ignition is retarded with the increase of Al content in alloy. Chip ignition studies are conducted at depths of cut $(1 \div 1000 \mu \mathrm{m})$ that are rarely applied in industrial conditions. In the depth of cut range of $1 \div 80$ $\mu \mathrm{m}$, chip ignitron during machining was observed $[6,7,20]$.

For theoretical considerations, the undeformed chip thickness is of great significance in modelling the cutting process. In studies, several models for determining chip thickness are introduced, beginning from basic, such as linear or circular interpolation [13], to more advanced analysis of actual tool trajectory in trochoidal tool path. The local undeformed chip thickness can be calculated from the equation of so-called transcendental deduction [10].
The classification of chips can be adopted from the Polish Norm PN-ISO 3685:1996 (and its English equivalent ISO 3685:1993 Tool-life testing with single-point turning tools) [16]; however, the standard in question concerns turning steel or cast iron workpiece with high-speed steel, cemented carbide or ceramic tools. In addition, chip characteristics are dependent on other factors, e.g.: workpiece material, cutting edge material and geometry, its wear and position, cutting parameters and other cutting conditions. Furthermore, the importance of cutting tool geometry, stress and strain conditions, i.e. decohesion of material in chip formation zone $[5,8]$.

Magnesium chip morphology is another factor of considerable significance in safety of machining. The methodology for the evaluation of machining safety should include elements that will enable determination of built-up or burnt surfaces on the chip. Such a risk occurs when the melting point temperature of a workpiece material is reached during machining (for $\mathrm{Mg}$ alloys approx. $500^{\circ} \mathrm{C}$ ). The concept of chip morphology concerns mainly chip structure and geometry. Magnesium alloy chips have a characteristic structure: on the one hand, their surface is smooth (as a result of the contact between the rake face and chip), on the other hand, frequently chips of lamellar structure are formed. Lamellae are regular structures layered in parallel to each other $[4,6,9]$.

During HSM, increasing cutting speed (at constant material removal rate) results in decrease in cutting forces, which in turn decreases the amount of heat generated in the cutting zone and minimises chip deformation [1]. It is therefore crucial to realise the machining process within cutting data denoting high-speed machining.

At temperatures exceeding $500^{\circ} \mathrm{C}$ small fractions of loose $\mathrm{Mg}$ chips can ignite, and $623^{\circ} \mathrm{C}$ is the nominal ignition temperature for magnesium in the presence of oxygen. At the temperature of $650^{\circ} \mathrm{C}$, magnesium melts, $1107^{\circ} \mathrm{C}$ is magnesium boiling point and the combustion temperature is above $2000^{\circ} \mathrm{C}$ (ignition point is lower than melting point) [15].

\section{PROGRAMME, METHODOLOGY AND AIM OF STUDY}

Figure 1 shows a schematic plan for the conducted research works. The purpose of the study was to analyse technological considerations for 


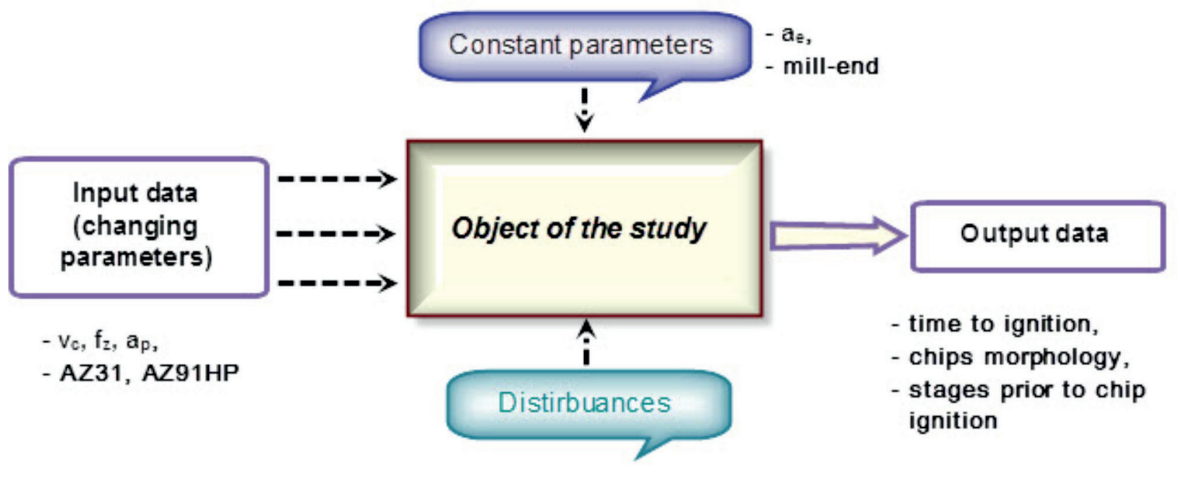

Fig. 1. General plan of study

selecting such cutting data as: cutting speed, feed and depth of cut, with a view to risk of ignition, defined by indices analysed in the study. Selecting proper relations between the cutting parameters in question is paramount to obtaining excellent stability and effectiveness of the process. The main aim was to analyse ignition time, stages in chip morphology change prior to ignition and microscopic observation of chips.

Milling operations were carried out on a vertical machining centre Avia VMC800HS with a TiAlN-coated carbide cutter $16 \mathrm{~mm}$ in diameter. The selected working engagement was constant, at $\mathrm{a}_{\mathrm{e}}=14 \mathrm{~mm}$, and changing technological parameters of milling were: $a_{p}=(0.5 \div 6) \mathrm{mm}, \mathrm{f}_{\mathrm{z}}=(0.05 \div 0.3)$ $\mathrm{mm} /$ tooth and $\mathrm{v}_{\mathrm{c}}=(400 \div 1200) \mathrm{m} / \mathrm{min}$. The tests were conducted on two types of magnesium alloys: AZ91HP cast alloy and AZ31 alloy for plastic working applications. The two analysed materials are widely used in industry. Table 1 shows the chemical composition of the analysed magnesium alloys, e.g. AZ91 alloy has an $89.587 \%$ content of pure $\mathrm{Mg}$, while AZ31 95.31\%.

Metallographic examination of chips was carried out with Leica DFC450-C digital microscope camera. Time to ignition and ignition temperature were measured on a custom test set-up outside of the machine tool. With a view to comparative analysis, stages in chip morphology change prior to chip ignition were analysed with Phantom 9.1 high-speed camera. Ignition time measurement was carried out 5 times for specified technological parameters of milling.
For the purpose of description, two terms are used in the paper: chip fraction and chip fragmentation. Fraction is a population of elements of a particular size or dimensions. Fragmentation is a phenomenon occurring during machining consisting in formation of an intermediate chip fraction of different shape and mass, alongside the leading fraction (prevailing and characteristic). It is an unfavourable condition due to the danger of ignition of small chip fractions and swarf polluting the workspace of the machine tool. The division into leading (main) fraction and intermediate fractions was based on the shape and mass of chip. The shape of chip determined the leading fraction (of the highest mass per unit area and the most representative in quantitative terms) and intermediate fractions. The intermediate fraction was defined in two stages: as a fraction dissimilar to the leading fraction, and as a fraction of mass per unit area which is approx. 50\% lower than the chip of leading fraction.

Figure 2 shows a visualisation of a set-up for measurement of time to ignition of chip formed during milling at changing technological parameters.

The methodology and the programme of tests determine that it is important to search for the suitable set of solutions, for which the aims of the work are realised to the greatest extent, in the space of independent variables.

Figure 3 shows a sheathed thermocouple dedicated for surface temperature measurements (of e.g. heating plate) and a temperature controller. The thermocouple is designed for measuring

Table 1. Chemical composition of tested magnesium alloys $[17,18]$

\begin{tabular}{|c|c|c|c|c|c|c|c|c|}
\hline \multirow{2}{*}{ Alloy } & \multicolumn{8}{|c|}{ Chemical composition [\%] } \\
\hline & $\mathrm{Cu}$ & $\mathrm{Mn}$ & $\mathrm{Mg}$ & $\mathrm{Zn}$ & $\mathrm{Si}$ & $\mathrm{Fe}$ & $\mathrm{Al}$ & other \\
\hline AZ31 & 0.05 & $0.2-0.1$ & rest & $0.7-1.3$ & - & - & $2.5-3.5$ & $\mathrm{Ca} 0.04$ \\
\hline AZ91HP & 0.016 & 0.17 & rest & 0.72 & 0.03 & 0.002 & 9.45 & Ni 0.025 \\
\hline
\end{tabular}




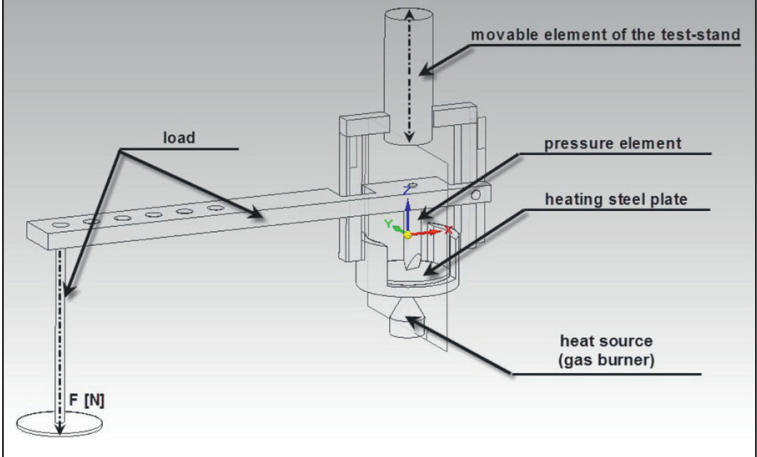

Fig. 2. Chip ignition test set-up

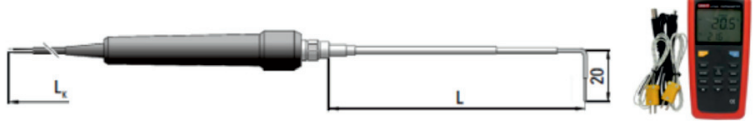

Fig. 3. Type K sheathead thermocouple (thermocouple TP-102a-120, sheath material NiCr-NiAl) and UT-320 temperature controller [22]

temperature of liquids, gases and on the surface [22]. The temperature sensor works with different input types, including thermocouples $\mathrm{K}, \mathrm{J}, \mathrm{T}$ and $\mathrm{E}$, providing measurement accuracy of $\pm[0.2 \%+$ $\left.0.6^{\circ} \mathrm{C}\right]$. The types of thermocouples denote the sheath material, i.e.: $\mathrm{J}-\mathrm{Fe}-\mathrm{CuNi}, \mathrm{T}-\mathrm{Cu}-\mathrm{CuNi}$, $\mathrm{E}-\mathrm{NiCr}-\mathrm{CuNi}$. The type of a thermocouple used depends on the range of temperatures to be measured.

Time to ignition was measured 5 times for each chip fraction. In addition, maximum and average temperature of the heating plate was given.

\section{TEST RESULTS AND ANALYSIS}

Figure 4 shows the impact of cutting speed $v_{c}$ and feed per tooth $f_{z}$ on average time to chip ignition.

There is no clear-cut correlation between the change of $v_{c}$ and $f_{z}$ and increase or decrease of time to ignition of leading and intermediate fractions of chips. In the case of $\mathrm{v}_{\mathrm{c}}$ change and the leading chip fraction, AZ91HP magnesium alloy, the average time to ignition rises whereas in AZ31 no particular tendency is observed (Fig. $4 \mathrm{a})$. The change of feed per tooth (Fig. 4b) produced two notable tendencies. At $f_{z}=(0.05 \div 0.15)$ $\mathrm{mm} /$ tooth time to ignition for the leading chip

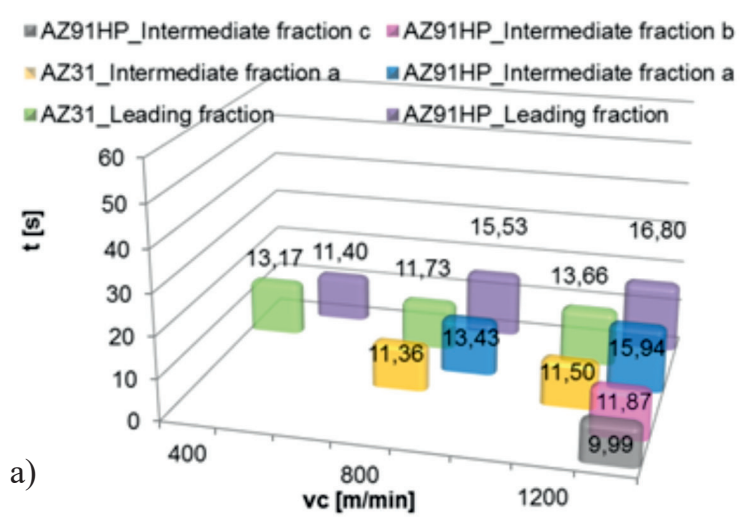

b) $\triangle A Z 31 \_$Intermediate fraction $=A Z 91 \mathrm{HP}$ Internediate fraction

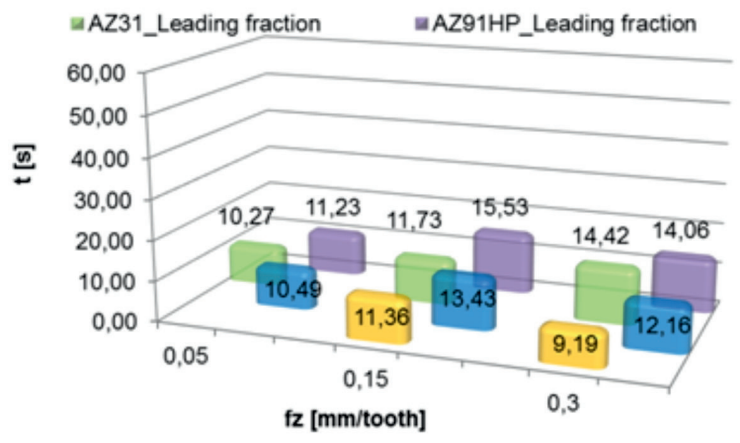

Fig. 4. Time to ignition of different chip fractions at different milling parameters: a) cutting speed $\mathrm{v}_{\mathrm{c}}\left(\mathrm{f}_{\mathrm{z}}=\right.$ $0.15 \mathrm{~mm} /$ tooth, $\mathrm{a}_{\mathrm{p}}=6 \mathrm{~mm} ; \operatorname{Tmax}=525.4 \pm 1.7^{\circ} \mathrm{C}$, Tav $\left.=521.8 \pm 1.6^{\circ} \mathrm{C}\right)$, and $\left.\mathrm{b}\right)$ feed per tooth $\mathrm{f}_{\mathrm{z}}\left(\mathrm{v}_{\mathrm{c}}=800 \mathrm{~m} /\right.$ $\min , \mathrm{a}_{\mathrm{p}}=6 \mathrm{~mm} ; \operatorname{Tmax}=529.3 \pm 1.7^{\circ} \mathrm{C}$, $\left.\mathrm{Tav}=525.8 \pm 1.7^{\circ} \mathrm{C}\right)$

fraction increases. At $f_{z}=(0.15 \div 0.3) \mathrm{mm} /$ tooth, the following effects are observed: time to ignition of AZ91HP alloy chips decreases, whereas in AZ31 alloys, further increase is observed.

An important observation is that, as shown in Figure 4, even in intermediate chip fractions, in particular in "intermediate fraction c", no sharp decrease in time to ignition occurs, compared to the leading chip fraction, despite a great difference in mass per unit of both fractions (as in [8]). This information is of great significance to safety precautions during machining, as even the intermediate fraction does not ignite instantly: even chips of small mass $(\mathrm{m}=0.0003 \mathrm{~g})$ require a certain length of time to ignite.

Figure 5 analyses the impact of depth of cut $a_{p}$ on average time to chip ignition. In the case of the leading chip fraction, the change in the depth of cut (Fig. 5) resulted in no significant change of 
a) $\triangle A Z 91 H P \_$Intermediate fraction $c \triangle A Z 91 \mathrm{HP} \_$Intermediate fraction $b$

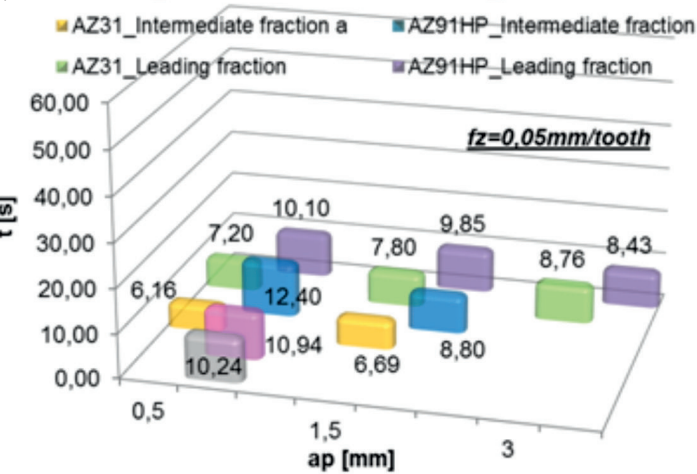

b) $\triangle A Z 91 \mathrm{HP} \_$Intermediate fraction $c=A Z 91 \mathrm{HP} \_$Intermediate fraction $\mathrm{b}$ $\square$ AZ31_Intermediate fraction a $\quad$ AZ91HP_Intermediate fraction a

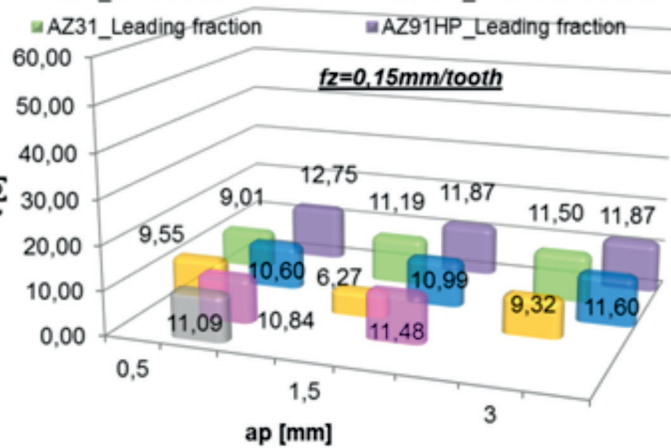

Fig. 5. Time to ignition of different chip fractions at different depths of cut ap: a) $\mathrm{f}_{\mathrm{z}}=0.05 \mathrm{~mm} /$ tooth; $\left.\operatorname{Tmax}=520.8 \pm 1.6^{\circ} \mathrm{C}, \mathrm{Tav}=515.0 \pm 1.6^{\circ} \mathrm{C} ; \mathrm{b}\right) \mathrm{f}_{\mathrm{z}}=0.15$ $\mathrm{mm} /$ tooth; $\operatorname{Tmax}=525.2 \pm 1.7^{\circ} \mathrm{C}, \operatorname{Tav}=521.2 \pm 1.6^{\circ} \mathrm{C}$

time to ignition. No direct correlation was noted between the change in average mass per unit of the leading chip fraction on its average time to ignition parameter. The analysis of intermediate chip fractions showed that at changing depth of cut (Fig. 5) in the majority of cases the time to ignition values were comparable to that of the leading chip fraction. Longer time to ignition observed in AZ91HP chips could result from differences in alloy additions in the analysed $\mathrm{Mg}$ alloys.

The characteristic changes in chip morphology at stages prior to ignition were analysed for the following technological parameters: $a_{p}=1.5 \mathrm{~mm}$ $\mathrm{f}_{\mathrm{z}}=0.05 \mathrm{~mm} /$ tooth $\mathrm{v}_{\mathrm{c}}=300 \mathrm{~m} / \mathrm{min}$. The examination was carried out to present the chip morphology stages leading to chip ignition. Figs. 6 and 7 show phases prior to ignition of analysed chip fractions.

Fig 6. shows changes in chip morphology preceding ignition of AZ31 alloy chip.

Chip ignition, observed on a special heating plate, is preceded by strong thermal deformation of the analysed chip in response to high tempera-
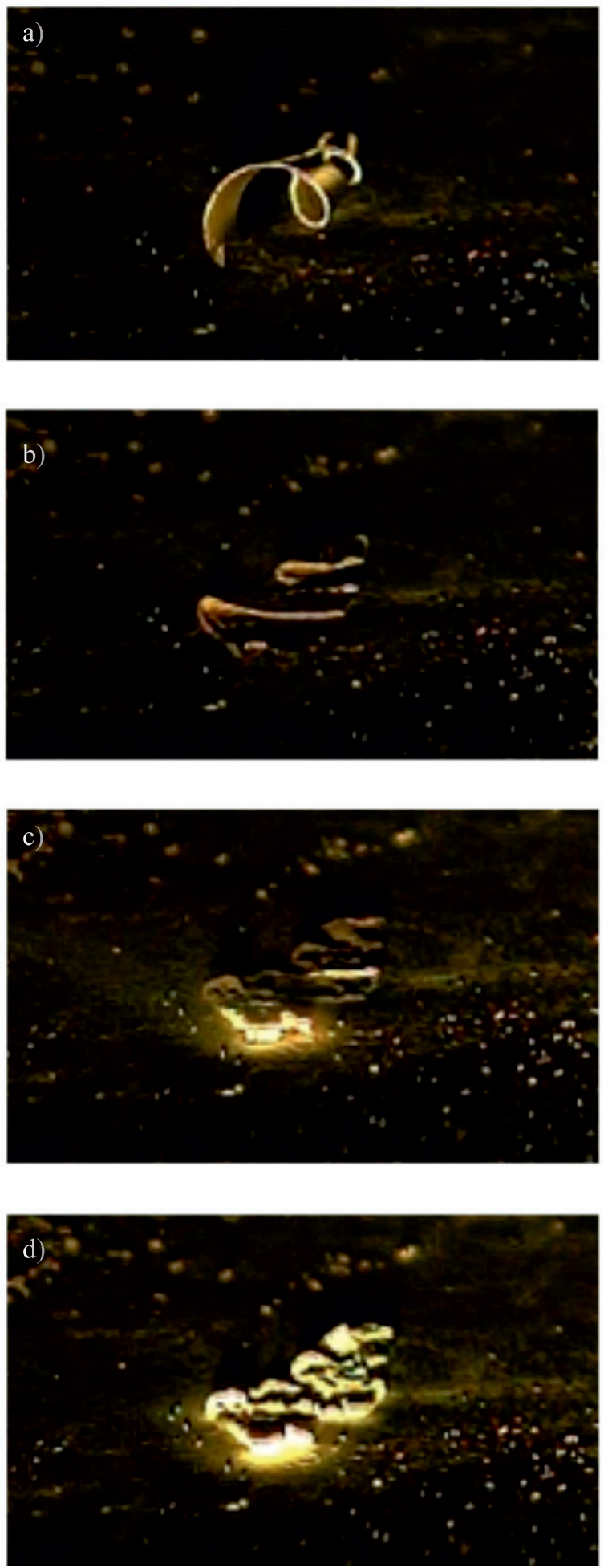

Fig. 6. Subsequent stages prior to AZ31 alloy chip ignition: a) the contact of chip with the heating plate, b) thermal deformation of chip, c) initial ignition of chip, d) full ignition of chip; $a_{p}=1.5 \mathrm{~mm} \mathrm{f}_{z}=0.05$ $\mathrm{mm} /$ tooth $\mathrm{v}_{\mathrm{c}}=300 \mathrm{~m} / \mathrm{min}$

ture. The vision camera used in tests provided images that allowed us to measure time to ignition and time needed to cause thermal deformation of chip, the latter measured from the moment of 
chip-plate contact to chip deformation. The test provides crucial information from the point of view of ensuring secure conditions of machining in terms of potential chip ignition occurrence.

Additional tests for the leading fraction chip ignition were conducted for chips produced at the following cutting conditions: AZ91HP alloy, $\mathrm{v}_{\mathrm{c}}=$ $1200 \mathrm{~m} / \mathrm{min}, \mathrm{f}_{\mathrm{z}}=0.15 \mathrm{~mm} /$ tooth, $\mathrm{a}_{\mathrm{p}}=6 \mathrm{~mm}$. The ignition of the leading fraction chip was initiated by direct ignition from intermediate chip fractions (the intermediate fraction was supposed to ignite the leading fraction). 5 test attempts were carried out for each intermediate chip fraction, then the leading fraction chip was replaced and the procedure was repeated. In chips produced in the aforementioned conditions the following observations were made:

- failure to ignite the leading fraction chips by two intermediate fractions: "b" (average mass $0.0071 \mathrm{~g}$ ) and "c" (average mass $0.0003 \mathrm{~g}$ ),

- successful ignition of the leading fraction chips by the intermediate fraction "a" (average mass $0.0176 \mathrm{~g}$, i.e. approx. a half of the leading fraction mass).

The conducted tests conclude that even if small chips are ignited during milling, the remaining larger chip fractions will not become ignited. Obviously, it is imperative that machining parameters that could cause excessive fragmentation of chips potentially leading to ignition during the process should not be applied, as the formed chip could additionally leave swarf and debris inside the machine tool.

Figure 7 shows phases prior to ignition of AZ91HP alloy chip.

Metallographic examination of thermally deformed chip morphology becomes an important tool in analysis of ignition risk during milling. Leica DFC450-C digital microscope camera enabled us to analyse the built-up edges occurring on the side surface of formed $\mathrm{Mg}$ chip. Such analysis was conducted for chip produced at maximum (in the analysed study) technological parameters of machining.

Figure 8 shows photographic images of the following magnesium alloy chips: chips formed at maximum cutting speed $\mathrm{v}_{\mathrm{c}}$ and feed per tooth $\mathrm{f}_{\mathrm{x}}$ (Fig. 8a and 8b), chips subjected to high temperature (approx. $500{ }^{\circ} \mathrm{C}$ ), chips where no ignition occurred (Fig. 8c and 8d), chips that succumbed to ignition on the heating plate at approx. $500{ }^{\circ} \mathrm{C}$ (Fig. 8e and 8f).
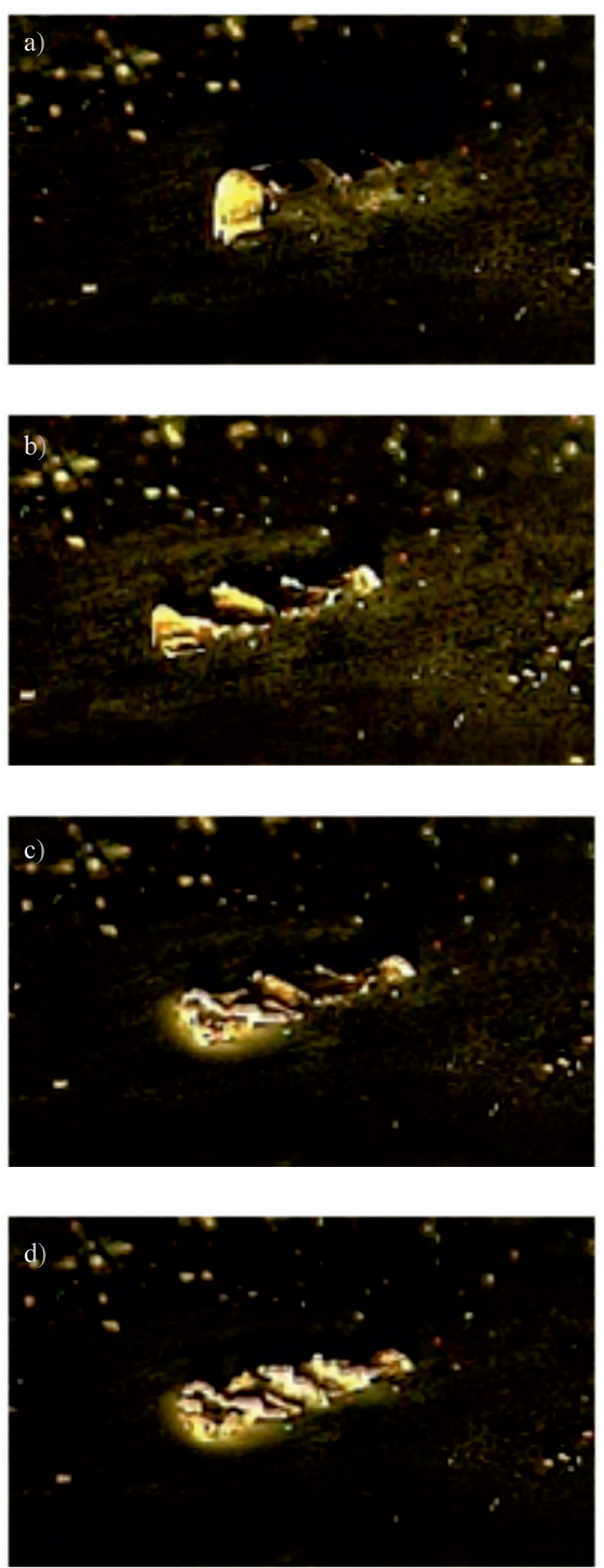

Fig. 7. Subsequent changes in chip geometry prior to AZ91HP alloy chip ignition: a) the contact of chip with the heating plate, $b$ ) thermal deformation of chip, c) initial ignition of chip, d) full ignition of chip;

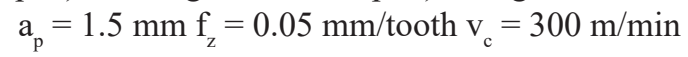

No characteristic built-up or burnt surfaces or edges of chips presented in Figures $8 \mathrm{a}$ and $8 \mathrm{~b}$ can be noticed. The surface of chips shown in Figure $8 \mathrm{c}$ and $8 \mathrm{~d}$ is considerably darker compared to 

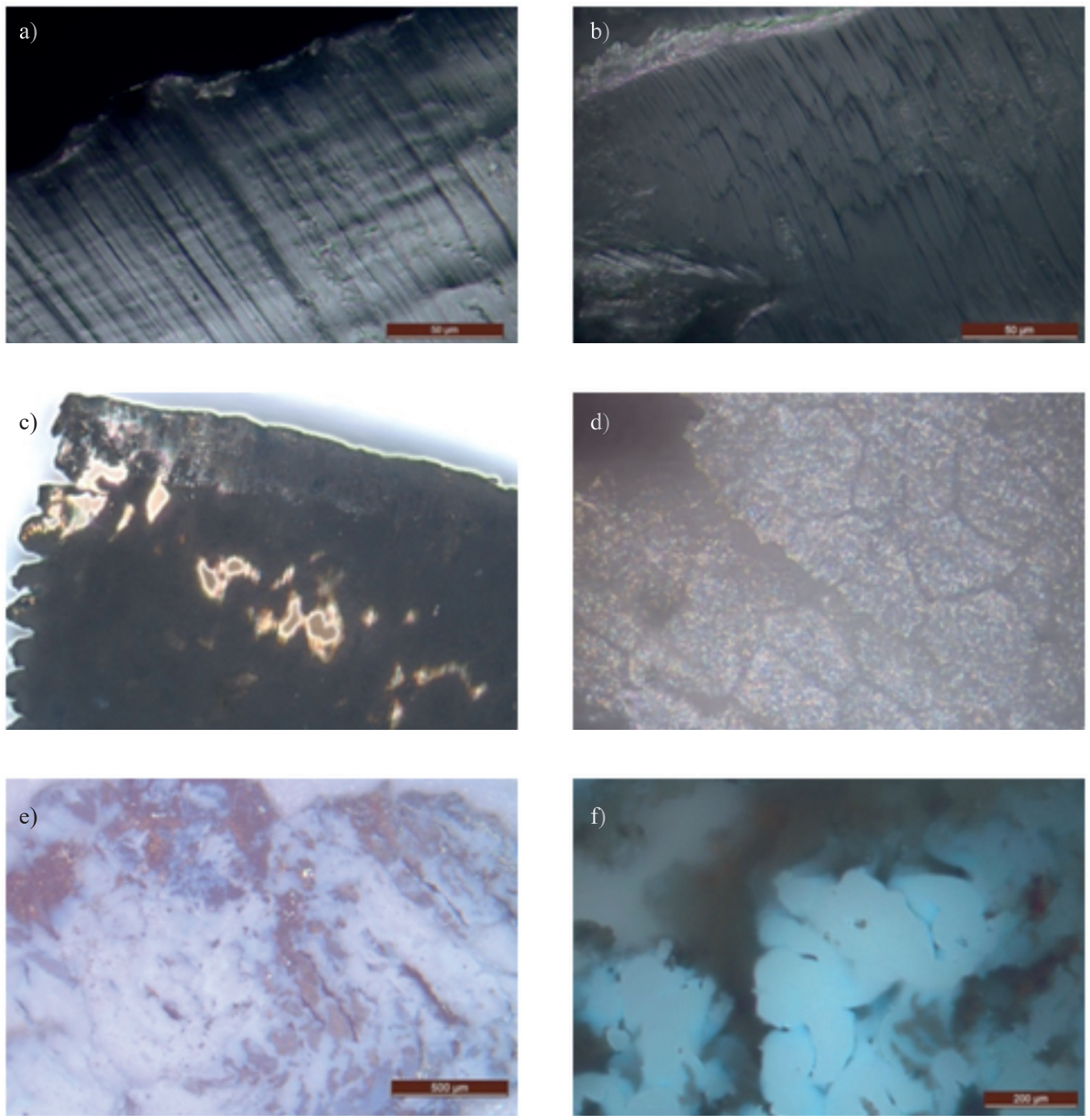

Fig. 8. Metallographic images of Mg alloy chips: a) AZ91HP alloy ( $\left.v_{c}=1200 \mathrm{~m} / \mathrm{min}\right)$, b) AZ31 alloy $\left.\left(\mathrm{v}_{\mathrm{c}}=1200 \mathrm{~m} / \mathrm{min}\right), \mathrm{c}, \mathrm{d}\right)$ chip that did not ignite when subjected to high temperature $\left(\approx 500^{\circ} \mathrm{C}\right)$, e, f) $\mathrm{Mg}$ alloy ignition products

chips immediately after cutting. This occurred as a result of strong oxidation of chip surface initiated at the point of chip-plate contact. The images in Figures $8 \mathrm{e}$ and $8 \mathrm{f}$ show ignition products on the surface of machined chips.

\section{CONCLUSIONS}

The conducted analytical and experimental works lead to the following general conclusions:

1. Chip fragmentation is an unfavourable phenomenon in machining, mainly due to a high- er risk of ignition of intermediate fractions of chips and debris in the workspace.

2. The conducted tests indicate that in the majority of cases longer time to ignition was noted in AZ91HP cast alloy chips; this could result from a higher content of alloy components and lower content of pure Mg.

3. Time to ignition was in the range of several to tens of seconds, i.e. several times more than the actual chip formation time.

4. Ignition of $\mathrm{Mg}$ alloy chips is preceded by strong thermal deformation of chip, observed in high-speed camera images. 
5. Ignition of the leading fraction of chips can be initiated by an ignited intermediate fraction only if the mass of intermediate fraction chips is equal to or higher than approx. 50\% of the leading fraction chip mass. In practice, this means that the uncontrolled selfignition of the most dangerous intermediate dust chip fraction cannot initiate ignition of the leading fraction.

6. The presented metallographic images show that no products of ignition or strong oxidation were present on the chip surface. This conclusion is of great significance to machining safety during dry milling of analysed magnesium alloys.

7. Microscopic examination of chip formed during machining at maximum analysed technological parameters of cutting showed distinctly visible fragments of chips. No characteristic built-up edges were observe, which could indicate a cutting zone dangerous from the point of view of self-ignition.

\section{REFERENCES}

1. Adamski W. Manufacturing development strategies in aviation industry. Advances In Manufacturing Science and Technology, 34(3), 2010, 73-84.

2. Akyuz B. Machinability of magnesium and its alloys. TOJSAT: The Online Journal of Science and Technology, 1(3), 2011, 31-38.

3. Arai M., Sato S., Ogawa M. and Shikata H.I. Chip Control in Finish Cutting of Magnesium Alloy. Journal of Materials Processing Technology, 62(4), 1996, 341-344.

4. Fang F.Z., Lee L.C. and Liu X.D. Mean Flank Temperature Measurement in High Speed Dry Cutting. Journal of Materials Processing Technology, 167(1), 2005, 119-123.

5. Guo Y.B. and Salahshoor M. Process mechanics and surface integrity by high-speed dry milling of biodegradable magnesium-calcium implant alloys, CIRP Annals - Manufacturing Technology, 59(1), 2010, 151-154.

6. Hou J.Z., Zhou W. and Zhao N. Methods for Prevention of Ignition during Machining of Magnesium Alloys. Key Engineering Materials, 447-448, 2010, 150-154.

7. Hou J.Z., Zhou W. and Zhao N. Effect of Cutting Parameters on Ignition of AM50A Mg Alloy dur- ing Face Milling. Materials and Manufacturing Processes, 25(10), 2010, 1048-1051.

8. Kuczmaszewski J. and Zagórski I.: Badania fragmentowania wiórów w procesie frezowania stopów magnezu. Mechanik, 8-9, 2014, 321-328.

9. Kuczmaszewski J. and Zagórski I. Badania masy, temperatury zapłonu oraz temperatury wiórów podczas skrawania wybranych stopów magnezu. Mechanik, 10, 2012, 824-828.

10. Li H.Z., Liu K. and Li X.P. A new method for determining the undeformed chip thickness in milling. Journal of Materials Processing Technology, 113(1-3), 2001, 378-384.

11. Lin P.-Y., Zhou H., Li W., Li W.-P., Sun N. and Yang, R. Interactive effect of cerium and aluminum on the ignition point and the oxidation resistance of magnesium alloy. Corrosion Science, 50(9), 2008, 2669-2675.

12. Liu M., Shih D.S., Parish C. and Atrens A. The ignition temperature of $\mathrm{Mg}$ alloys WE43, AZ31 and AZ91. Corrosion Science, 54, 2012, 139-142.

13. Lotfi Sai, Bouzid W. and Zghal A. Chip thickness analysis for different tool motions for adaptive feed rate. Journal of Materials Processing Technology, 204(1-3), 2008, 213-220.

14. Matuszak J. and Zaleski K. Effect of Brushing Parameters Upon Edge States After Wire Brushing of AZ91HP Magnesium Alloy, Advances in Science and Technology Research Journal, 7(20), 2013, 55-60.

15. Oczoś K.E. Rozszerzenie granic stosowalności stopów magnezu. Mechanik 5-6, 2009, 386-400.

16. Polska Norma. Badanie trwałości noży tokarskich punktowych, PN-ISO 3685:1996.

17. Polska Norma. Magnez i stopy magnezu - Gąski i odlewy ze stopów magnezu, PN-EN 1753:2001.

18. Polska Norma. Magnez i stopy magnezu - Anody, gąski i odlewy z magnezu i stopów magnezu - System oznaczenia, PN-EN 1754:2002.

19. Ravi Kumar N.V., Blandin J.J., Suery M. and Grosjean E. Effect of alloying elements on the ignition resistance of magnesium alloys. Scripta Materialia, 49(3), 2003, 225-230.

20. Zhao N., Hou J. and Zhu S. Chip ignition in research on high-speed face milling AM50A magnesium alloy. Second International Conference on Mechanic Automation and Control Engineering, Inner Mongolia, China 2011, 1102-1105.

21. Zhou H., Li W., Wang M. and Zhao Y. Study of ignition proof AZ91D magnesium alloy chips with cerium addition. Journal of Rare Earth, 23(4), 2005, 466-469.

22. http://www.czaki.pl/, accessed on: 9.04.2010. 